\title{
Processos de trabalho da assistência estudantil no ensino superior: uma percepção dos assistentes sociais da Universidade de Brasília (UnB)
}

de Sant'anna, Marcia Costa; Nascimento de Almeida, Alexandre

Processos de trabalho da assistência estudantil no ensino superior: uma percepção dos assistentes sociais da Universidade de Brasília (UnB)

Administração Pública e Gestão Social, vol. 13, núm. 3, 2021

Universidade Federal de Viçosa, Brasil

Disponible en: https://www.redalyc.org/articulo.oa?id=351566982007 
Processos de trabalho da assistência estudantil no ensino superior: uma percepção dos assistentes sociais da Universidade de Brasília (UnB)

\begin{abstract}
Work processes of the student assistance in higher education: a perception of the social workers from University of Brasília (UnB)

Procesos de trabajo de asistencia estudiantil en la educación superior: una percepción de los trabajadores sociales de la Universidad de Brasilia (UnB)
\end{abstract}

Marcia Costa de Sant'anna

Universidade de Brasilia, Brasil

Redalyc: https://www.redalyc.org/articulo.oa?

marcia.dds.unb@gmail.com

Alexandre Nascimento de Almeida

Universidade de Brasilia, Brasil

alexalmeida@unb.br

$\mathrm{id}=351566982007$

Recepción: 06 Julio 2020

Aprobación: 04 Noviembre 2020

Publicación: 01 Julio 2021

\title{
Resumo:
}

Objetivo da pesquisa: O objetivo da pesquisa é analisar os processos de trabalho dos assistentes sociais na assistência estudantil da UnB.

Enquadramento teórico: Na última década ocorreu uma expansão e democratização das vagas no ensino superior público do Brasil. Essa expansão ampliou o número de estudantes em vulnerabilidade socioeconômica, demandando uma ampliação nos programas de assistência estudantil. Entretanto, o crescimento da assistência estudantil nas universidades não tem sido compatível com sua demanda, gerando problemas de gestão e falta de recursos e infraestrutura.

Metodologia: Os dados foram obtidos por meio da aplicação de questionário semiaberto para a equipe de assistentes sociais em um estudo de caso para a UnB. O instrumental analítico foi a análise de cluster.

Resultados: Os resultados desta pesquisa indicaram que existem poucos fatores positivos nos processos de trabalho na assistência estudantil da UnB, sugerindo a necessidade de intervenções em diferentes aspectos, a fim de acompanhar as transformações ocorridas nas universidades públicas brasileiras.

Originalidade: O tema (processos de trabalho da assistência estudantil) e a abordagem da pesquisa (percepção dos assistentes sociais) são pouco explorados na literatura nacional e internacional.

Contribuições teóricas e práticas: O estudo contribui para verificação empírica da teoria que cerca os modelos de administração pública e apresenta resultados práticos para a gestão da assistência estudantil, constatando o descompasso entre a demanda gerada pelas políticas de inclusão na UnB e os recursos financeiros e humanos para implementação dessas políticas, bem como aspectos a serem melhorados no que tange ao planejamento, ao treinamento e à comunicação no trabalho da assistência estudantil na UnB.

Palavras-CHAVE: gestão universitária, desigualdade social, gestão pública.

\section{Abstract:}

Research objective: The objective of the research is to analyze the perception of social workers about their work processes in student assistance at $\mathrm{UnB}$.

Theoretical framework: In the last decade there was an expansion and democratization of places in public higher education of Brazil. This expansion increased the number of students in socioeconomic vulnerability, demanding the expansion of student assistance programs. However, the growth of the student assistance at universities has not been compatible with its demand, creating management problems and lack of resources and infrastructure.

Methodology: Data were obtained through the application of a semi-open questionnaire to the social worker's staff in a case study for UnB. The analytical tool was cluster analysis.

Results: The results indicated that there are few positive factors in the work processes of student assistance at UnB, suggesting the need for interventions in different aspects, in order to follow the changes that have occurred in Brazilian public universities. 
Originality: The theme (student assistance work processes) and the research approach (perception of social workers) are little explored in national and international literature.

Theoretical and practical contributions: The study contributes to the empirical verification of the theory related to public administration models and presents practical results for the management of student assistance, verifying the mismatch between the demand generated by the inclusion policies at $\mathrm{UnB}$ and the financial and human resources for the implementation of these policies, as well as aspects to be improved regarding planning, training and communication in the work of student assistance at UnB.

KEYWORDS: university management, social inequality, public management.

\section{RESUMEN:}

Objetivo de la investigación: El objetivo de la investigación es analizar los procesos de trabajo de los trabajadores sociales en la asistencia al estudiante de la $\mathrm{UnB}$.

Marco teórico: En la última década ocurrió una expansión y democratización de los lugares en la educación superior pública en Brasil. Esta expansión aumentó el número de estudiantes en vulnerabilidad socioeconómica, exigiendo una expansión en los programas de asistencia estudiantil. Sin embargo, el crecimiento de la asistencia estudiantil en las universidades no ha sido compatible con su demanda, creando problemas de gestión y falta de recursos e infraestructura.

Metodología: Los datos se obtuvieron mediante la aplicación de un cuestionario semiabierto al equipo de trabajadores sociales en un estudio de caso para UnB. La herramienta analítica fue el análisis de cluster.

Resultados: Los resultados de esta investigación indicaron que hay pocos factores positivos en los procesos de trabajo en la asistencia estudiantil en $\mathrm{UnB}$, lo que sugiere la necesidad de intervenciones en diferentes aspectos, a fin de seguir los cambios que se han producido en las universidades públicas brasileñas.

Originalidad: El tema (procesos de trabajo de asistencia al estudiante) y el enfoque de investigación (percepción de los trabajadores sociales) son poco explorados en la literatura nacional e internacional.

Aportes teóricos y prácticos: El estudio contribuye a la verificación empírica de la teoría que envuelve los modelos de administración pública y presenta resultados prácticos para la gestión de la asistencia a los estudiantes, comprobando el desajuste entre la demanda generada por las políticas de inclusión en la UnB y los recursos financieros y humanos para la implementación de estas políticas, así como aspectos a mejorar en materia de planificación, formación y comunicación en la labor de atención al alumno en la UnB.

Palabras ClaVE: gestión universitaria, desigualdad social, gestión pública.

\section{INTRODUÇÃo}

Todo trabalho que ocorre em uma organização, segundo Gonçalves (2000), faz parte de algum tipo de processo. Portanto, uma instituição é o resultado da soma de cada um dos processos necessários para a obtenção de seu produto e (ou) serviço final, passando a haver uma busca pela melhoria dos processos de trabalho por maior desempenho, transparência e monitoramento, alcançando qualidade em seus resultados.

De acordo com Biazzi, Muscat e Biazzi (2011), os processos de trabalho no setor público brasileiro estão relacionados ao modelo burocrático, através de uma realidade que se volta, demasiadamente, às regras e normas, que acabam sendo consideradas como absolutas. O papel das regras e normas no modelo burocrático é de evitar arbitrariedades das ações públicas, bem como casos de nepotismo e corrupção. Entretanto, tem-se verificado algumas disfunções desse modelo, como morosidade do serviço público, exagerado apego aos regulamentos, excesso de formalismo, resistência a mudanças, despersonalização dos relacionamentos, exibição de sinais de autoridade e conflitos com o público. Essas disfunções justificam a busca de novos modelos, recentemente incluindo aspectos da administração privada, tais como descentralização, orientação para resultados, flexibilidade, competitividade interna e externa, transparência e prestação de contas. A questão-chave é a melhor combinação de procedimentos de ambos os modelos, atendendo, assim, ao interesse público em sua plenitude (Drumond, Silveira, \& Arlindo Silva, 2014; Costa \& Rocha, 2018).

A dificuldade de combinação de procedimentos de eficiência na administração pública pode ser observada nos processos de trabalho da assistência estudantil da Universidade de Brasília (UnB): apesar dos avanços obtidos com a implementação da assistência estudantil como política pública, em especial, com os decretos n. 6.096/2007 (Programa de Apoio a Planos de Reestruturação e Expansão das Universidades Federais 
[REUNI]), n. 7.234/2010 (Programa Nacional de Assistência Estudantil [PNAES]) e n. 7.824/2012 (Lei de Cotas) (Decreto n. 6.096, 2007; Decreto n. 7.234, 2010; Lei n. 12.711, 2012), os processos de trabalho da assistência estudantil podem ser aprimorados.

A assistência estudantil insere-se como uma das principais estratégias para o enfrentamento das desigualdades sociais dos estudantes universitários. Especificamente na UnB, essa estratégia é alcançada por meio do Ato da Reitoria n. 266/94, sendo executada pela Diretoria de Desenvolvimento Social (DDS), vinculada ao Decanato de Assuntos Comunitários (DAC) da universidade (UnB, 2020).

Seguindo o Decreto do PNAES, a política de assistência estudantil da UnB é voltada aos estudantes em vulnerabilidade socioeconômica. Em geral, a implementação dessa política passa por um processo de avaliação que tem por objetivo classificar o estudante conforme a sua vulnerabilidade socioeconômica. $\mathrm{Na} U n \mathrm{~B}$ o principal critério para essa classificação é que a renda familiar per capita do estudante não seja superior a um salário mínimo e meio (Ferreira, 2020). A formação dos estudantes em vulnerabilidade socioeconômica impõe desafios complexos para a assistência estudantil. Em geral, os estudantes atendidos pela assistência estudantil possuem uma formação de baixa qualidade no ensino básico e apresentam maior predisposição a sofrerem problemas de ordem psicológica, devido a questões familiares, distância de casa, falta de lazer, insegurança financeira, entre outros (Almeida \& Silva, 2020).

A materialização da assistência estudantil na DDS acontece, principalmente, a partir da oferta de programas específicos nos quais os assistentes sociais têm sido os maiores articuladores na mediação e acesso dos estudantes em situação de vulnerabilidade socioeconômica, uma vez que a avaliação socioeconômica, que é o requisito principal para esse acesso, é realizada somente pelos profissionais supracitados. Soma-se também a contribuição desses profissionais em vários outros processos de trabalho junto à DDS, destacando a magnitude do seu público-alvo frente ao baixo número de profissionais que compõem a equipe de trabalho na assistência estudantil da UnB.

Com a expansão e democratização do acesso à educação superior, a busca pelos programas de assistência estudantil tem crescido, ocorrendo, rotineiramente, a necessidade de prorrogação de prazos dos editais seletivos e nem sempre tem sido possível atender a todas as solicitações estudantis com a celeridade necessária.

A evolução da assistência estudantil na UnB pode ser dimensionada pela concessão do Auxílio Socioeconômico e da Bolsa Permanência, junto com a Bolsa Alimentação e o programa de moradia estudantil, que são os principais programas oferecidos aos estudantes em vulnerabilidade socioeconômica. $\mathrm{O}$ número de beneficiados por esses dois programas em 2011 foi de 1.006 estudantes, cresceu a uma taxa média de $21 \%$ ao ano até 2017, alcançando o pico de 3.359 bolsas concedidas. Em 2018 registrou-se a primeira queda na série histórica, totalizando 3.295 bolsas distribuídas (UnB, 2020).

Assim, torna-se necessário o aprimoramento nos processos de trabalho da assistência estudantil da UnB, principalmente pelo atual cenário de restrição dos gastos públicos e, consequentemente, da redução de nomeações de servidores pelas universidades, conforme determinado pela Emenda Constitucional $\mathrm{n}$. 95/2016, que previu, entre outras coisas, o controle de gastos públicos até 2036 (Emenda Constitucional n. 95, de 15 de dezembro de 2016). O presente estudo dialoga com a área de gestão de riscos e, nesse aspecto, as conclusões de Ferreira da Silva e Almeida (2020) para a Fundação Universidade de Brasília (FUB) contribuíram com as justificativas da pesquisa:

\footnotetext{
Verificou-se alguns fatos críticos relacionado à FUB: 1) a Universidade já gasta aproximadamente $84 \%$ de seu orçamento com despesas de pessoal (ativos, inativos e encargos), ou seja, não existe margem para aumentar esse gasto sem comprometer as outras despesas correntes (luz, água e manutenção) e os investimentos; 2) a faixa etária dos servidores indica que muitos já possuem tempo suficiente para aposentar, isto é, podem se retirar a qualquer momento ou em um futuro próximo; 3) por conta da EC 95/2016 é de se esperar que os órgãos não logrem preencher as vagas dos servidores aposentados, haja vista que o limite de gastos dos órgãos continuam comprometidos com as aposentadorias, o que pode gerar um risco de descontinuidade de algumas atividades da FUB (Ferreira da Silva \& Almeida, 2020, p. 251).
} 
O objetivo do trabalho é analisar a percepção dos assistentes sociais sobre a qualidade dos seus processos de trabalho na assistência estudantil da UnB, buscando contribuir com o arcabouço teórico que cerca os modelos de administração pública e apresentar resultados práticos para a gestão da assistência estudantil na UnB. O tema (processos de trabalho da assistência estudantil) e a abordagem da pesquisa (percepção dos assistentes sociais) são pouco explorados na literatura nacional e internacional, elevando o caráter de originalidade da pesquisa.

\section{Fundamentos Teóricos}

\subsection{Inclusão e assistência estudantil: marco legal após constituição de 1988}

A garantia do direito a educação é marcada por um amplo arcabouço legal. Porém, antes de citar algumas legislações que ocorreram após a promulgação da Constituição de 1988 (Constituição da República Federativa do Brasil, 1988), é importante mencionar a criação do Fórum Nacional de Pró-Reitores de Assuntos Comunitários e Estudantis (FONAPRACE), que ocorreu no final do ano de 1987, o qual se configurou como um grande aliado para o fortalecimento e implantação da assistência estudantil no ensino superior (Dutra \& Santos, 2017).

Como proposta para democratização do acesso ao ensino superior, em 24 de abril de 2007 foi implementado o Decreto n. 6.096, que sancionou o REUNI. De acordo com seu art. $1^{\circ}$, criou-se condições para ampliação do acesso e permanência na educação superior, tanto no que se refere à estrutura física como também em relação aos recursos humanos (Decreto n. 6.096 de 25 de abril de 2007).

Com objetivo de se obter maior definição e traçar diretrizes para a consolidação da assistência estudantil, o FONAPRACE colaborou com a criação, em 2007, do PNAES, que, em 12 de dezembro de 2007, foi instituído pela Portaria Normativa n. 39 e, em seguida, pelo Decreto n. 7.234 em 10 de julho de 2010 (Decreto n. 7.234 de 19 de julho de 2010).

O surgimento do PNAES ascende e institucionaliza a assistência estudantil como política pública, disponibilizando recursos orçamentários específicos para a educação superior pública federal, com intuito de garantir não só o acesso, mas também a permanência dos estudantes no ensino superior até a sua diplomação.

Desta forma, de acordo com o Decreto n. 7.234/10, o recurso deverá ser destinado às açóes elencadas e previstas no artigo $3^{\circ}$ do PNAES, nas áreas de moradia estudantil, alimentação, transporte, saúde, inclusão digital, cultura, esporte, creche, apoio pedagógico, acesso e aprendizagem aos portadores de deficiência e demais transtornos do desenvolvimento.

Em 2012 surge a Lei n. 12.711, que na sequência é regulamentada pelo Decreto n. 7.824, datado de 11 de outubro de 2012. Intitulada como a Lei de Cotas para ensino superior, prevê a reserva de vagas aos estudantes advindos do ensino médio de escolas públicas e autodeclarados pretos, pardos, indígenas e por pessoas com deficiência (Lei n. 12.711, 2012).

\subsection{Processos de trabalho no serviço público}

A administração pública, para Bresser-Pereira (2007), tem exigido um novo entendimento para o bom funcionamento de seus processos, no intuito de atingir seus objetivos, remetendo à ideia de que a modernização do modelo burocrático é essencial para gerar maior qualidade nos serviços ofertados.

Biazzi et al. (2011) analisaram que a estrutura organizacional do serviço público não é muito favorável para alcance de uma maior qualidade de resultados. Os autores afirmam que sua apresentação de modo departamentalizado, por meio de hierarquias bem definidas e com ascensão profissional por mérito e tempo de serviço, estabilidade funcional, cargos definitivos e salários fixados em tabela, por carreiras, contribuem 
para este déficit. Soma-se a falta de flexibilidade às regras, as quais são baseadas em situações mais comuns, sem levar em consideração as especificidades que compõem o todo.

Baldam, Valle e Rozenfeld (2014) afirmaram que pela finalidade que possui o serviço público, os processos de trabalho têm especificidades diferentes dos que ocorrem nas empresas privadas, já que, dentre os princípios da administração pública, a transparência e a publicidade devem ser obedecidas.

Embora a finalidade da administração pública, que é o bem público, seja bastante diferente da gestão privada, que se pauta na maximização do lucro, ambas buscam a eficiência. Segundo Castro Silva e Mattia (2016, p. 1057), a aproximação da gestão pública à privada "decorre da necessidade de perseguir um dos maiores objetivos da administração: a eficiência”. Os autores destacaram que o crescimento da influência privada na administração pública ocorreu a partir de meados da década de 1970, com a crise do Estado de bem-estar social (welfare state) e a escassez de recursos disponíveis, surgindo como alternativas propostas de reforma do Estado onde a eficiência era a meta principal dos governos, surgindo então a Nova Gestão Pública (NGP).

A NGP surgiu em contraposição ao modelo burocrático dentro de uma falsa dicotomia que opôs a burocracia weberiana à NGP (Leite, 2016). Porém, a burocracia não deve ser considerada um mal da administração pública, ela está a favor do bom uso que se queira fazer dela; se bem adotada, será sempre canal para um bom gerenciamento (Cordeiro, 2017). Ainda conforme Cordeiro (2017, p. 865), "de nada valerá existir um modelo tido como impecável, gerencial ou não, se suas características não forem respeitadas no seio organizacional”. Para Costa \& Rocha (2018, p. 635), “os valores de eficácia e eficiência, lidos como o alcance de metas ao menor custo, são importantes, mas não tão essenciais como a criação de probidade e responsabilidade" na administração pública.

\subsection{Processos de trabalho do Serviço Social na assistência estudantil}

Guerra (2000) definiu processo de trabalho para o Serviço Social como um conjunto de atividades práticas e reflexivas que são realizadas aos meios e as condições objetivas e subjetivas, visando alcançar seus objetivos. As condições objetivas estão ligadas à realidade material: meios de produção, ambiente, divisão do trabalho, objetos e áreas de intervenção. Já as condições subjetivas estão ligadas aos sujeitos e suas escolhas: suas qualificações e competências, seus referencias éticos e políticos, valores, entre outros.

A partir da década de 1980, Iamamoto (2015) destacou que o Serviço Social se insere, formalmente, como uma profissão para enfrentamento da questão social e como resposta às demandas de uma sociedade capitalista com uma conturbada relação entre capital e trabalho. Para a autora, a questão social é definida como o resultado das expressões das desigualdades da sociedade capitalista: injustiças sociais, econômicas, políticas e culturais. Raichelis (2011) destacou os desafios do cotidiano profissional do assistente social, pois lida com dura realidade enfrentada pelas classes subalternas na sociedade brasileira.

Trata-se de uma condição de trabalho que produz um duplo processo contraditório nos sujeitos assistentes sociais: a) de um lado, o prazer diante da possibilidade de realizar um trabalho comprometido com os direitos dos sujeitos violados em seus direitos, na perspectiva de fortalecer seu protagonismo político na esfera pública; b) ao mesmo tempo, o sofrimento, a dor e o desalento diante da exposição continuada à impotência frente à ausência de meios e recursos que possam efetivamente remover as causas estruturais que provocam a pobreza e a desigualdade social (Raichelis, 2011, p. 434).

Para Guerra (2000), a instrumentalidade do Serviço Social são os meios com que a profissão realiza a sua prática por meio de instrumentos. Ela é a mediação das atividades profissionais que permite a compreensão da realidade e especificidades cotidianas, a partir de ações dotadas de senso crítico sendo resultado das dimensões: técnico-instrumental, teórico-intelectual, ético-política e formativa.

Sousa (2008) faz a distinção entre instrumentos de trabalho "face a face" e indiretos. Os instrumentos "face a face" são: observação participante, a entrevista individual e grupal, dinâmica de grupo, as reuniões, as 
visitas domiciliares e institucionais. Os instrumentos indiretos são utilizados após o contato com o primeiro, ou seja, são os registros formais de trabalho como, por exemplo, as atas de reunião, livros de registro, diário de campo, relatório social e parecer social.

Complementando os instrumentos indiretos que constituem as ações profissionais do assistente social, Mioto (2009) fez importante menção sobre os estudos socioeconômicos, esses são a principal função do assistente social na assistência estudantil.

Operacionalmente, os estudos socioeconômicos/estudo social podem ser definidos como o processo de conhecimento, análise e interpretação de uma determinada situação social. Sua finalidade imediata é a emissão de um parecer - formalizado ou não - sobre tal situação, do qual o sujeito demandante da ação/usuário depende para acessar benefícios, serviços e/ou resolver litígios. Essa finalidade é ampliada quando se incluem a obtenção e análise de dados sobre as condições econômicas, políticas, sociais e culturais da população atendida em programas ou serviços, partir do conjunto dos estudos efetuados como procedimento necessário para subsidiar o planejamento e a gestão de serviços e programas, bem como a reformulação ou a formulação de políticas sociais (Mioto, 2009, p. 9).

\section{Procedimentos Metodológicos}

\subsection{Dados}

Os dados da pesquisa foram obtidos por meio da aplicação de questionário eletrônico semiaberto para o corpo de assistentes sociais vinculados à DDS e responsáveis pela assistência estudantil da UnB. A população de assistentes sociais da DDS no momento da pesquisa era de 18 servidores, dos quais apenas um não respondeu ao questionário, alcançando uma amostra de 17 servidores.

O questionário foi aplicado no período de 15 a 22 de agosto de 2018 e, antes do seu envio, realizou-se préteste com a participação de três especialistas que já trabalharam na diretoria mencionada. O pré-teste teve como objetivo avaliar as questões do questionário quanto a sua sequência, forma e conteúdo, verificando a clareza e relevância das questões para o tema abordado.

O questionário foi dividido em duas partes, a primeira com perguntas sobre o perfil dos respondentes e a segunda com afirmações que analisaram a percepção dos assistentes sociais a respeito da situação dos seus processos de trabalho na assistência estudantil.

A primeira parte do questionário teve como objetivo caracterizar a amostra, pedindo para os respondentes indicarem o sexo, idade, grau de instrução e experiência na DDS. Em pesquisas dessa natureza, onde é avaliada a percepção dos especialistas, o conhecimento do perfil dos participantes contribui para o entendimento da sua opinião e das limitações da pesquisa.

$\mathrm{Na}$ segunda parte, o questionário foi subdivido em 6 (seis) categorias principais, cada categoria com 4 (quatro) afirmações, totalizando 24 (vinte e quatro) variáveis. Para este estudo foram definidas as seguintes categorias: 1) Gestão de políticas educacionais; 2) Estilo de gestão da DDS; 3) Estruturas e normas; 4) Treinamento e capacitação; 5) Comunicação e 6) Instrumentais utilizados.

Ainda sobre o desenvolvimento do questionário, foi solicitado aos participantes que indicassem o seu grau de percepção diante das 24 variáveis pré-definidas, utilizando a Escala de Likert (1932) com cinco atributos de concordância: 1) Concordo totalmente (CT); 2) Concordo (C); 3) Indiferente (I); 4) Discordo (D) e 5) Discordo totalmente (DT). Após indicarem a sua percepção nos atributos de concordância, os participantes foram convidados a justificarem suas respostas em um espaço aberto, o que facilitou o entendimento do seu posicionamento nas questões fechadas.

O Quadro 1 apresentou um resumo das 24 afirmações do questionário referentes às variáveis que avaliaram os processos de trabalho da assistência estudantil na $\mathrm{UnB}$, relacionando-as com suas respectivas categorias e definindo siglas, o que facilitou a apresentação dos resultados. 
Quadro 1 - Categorias e suas variáveis conforme questionário aplicado

\begin{tabular}{|c|c|c|c|c|c|}
\hline $\begin{array}{l}\text { Categoria 1 - } \\
\text { Gestão de } \\
\text { políticas } \\
\text { educacionais }\end{array}$ & $\begin{array}{l}\text { Categoria } 2 \text { - } \\
\text { Estilo de } \\
\text { gestão da DDS }\end{array}$ & $\begin{array}{l}\text { Categoria } 3 \\
- \\
\text { Estruturas } \\
\text { e normas }\end{array}$ & $\begin{array}{l}\text { Categoria } 4 \\
\text {-Capacitação e } \\
\text { treinamento }\end{array}$ & $\begin{array}{l}\text { Categoria } 5 \text { - } \\
\text { Comunicação }\end{array}$ & $\begin{array}{l}\text { Categoria } 6 \text { - } \\
\text { Instrumentais } \\
\text { utilizados }\end{array}$ \\
\hline $\begin{array}{l}\text { Mudanças } \\
\text { nas políticas } \\
\text { educacionais } \\
\text { de ensino } \\
\text { superior sem } \\
\text { diálogo } \\
\text { prévio com as } \\
\text { universidades } \\
\text { (M.Pg) }\end{array}$ & $\begin{array}{l}\text { Condução da } \\
\text { gestão da DDS } \\
\text { de forma } \\
\text { organizada e } \\
\text { planejada } \\
\text { (A.Pd) }\end{array}$ & $\begin{array}{l}\text { Orientações } \\
\text { formaise } \\
\text { claras sobre } \\
\text { as } \\
\text { atribuiçōes } \\
\text { dos A.S. } \\
\text { (O.Fa) }\end{array}$ & $\begin{array}{l}\text { Existência de } \\
\text { política de } \\
\text { treinamento aos } \\
\text { novos } \\
\text { profissionais do } \\
\text { setor (P.Tr) }\end{array}$ & $\begin{array}{l}\text { Facilidade no } \\
\text { acesso as } \\
\text { informações } \\
\text { sobre A.E. } \\
\text { (F.Ai) }\end{array}$ & $\begin{array}{l}\text { Teoria como } \\
\text { diferente da } \\
\text { prática no trabalho } \\
\text { (T.Pa) }\end{array}$ \\
\hline $\begin{array}{l}\text { PNAES: } \\
\text { aplicação } \\
\text { Conforme a } \\
\text { legislação } \\
\text { (P.Al) }\end{array}$ & $\begin{array}{l}\text { Liberdade } \\
\text { para propor } \\
\text { modificações } \\
\text { sem } \\
\text { retaliações } \\
\text { (L.Mp) }\end{array}$ & $\begin{array}{l}\text { Quantidade } \\
\text { de A.S } \\
\text { atende à } \\
\text { demanda } \\
\text { (Q.AS) }\end{array}$ & $\begin{array}{l}\text { Recebimento de } \\
\text { informações } \\
\text { sobre os } \\
\text { processos de } \\
\text { trabalho no } \\
\text { ingresso ao } \\
\text { setor (I.PS) }\end{array}$ & $\begin{array}{l}\text { Frequência e } \\
\text { quantidade de } \\
\text { reuniốes são } \\
\text { Suficientes } \\
\text { (F.Qr) }\end{array}$ & $\begin{array}{l}\text { Padronização nos } \\
\text { instrumentais para } \\
\text { todos os campi } \\
\text { (P.IC) }\end{array}$ \\
\hline $\begin{array}{l}\text { Distribuição e } \\
\text { execução de } \\
\text { valores do } \\
\text { PNAES na } \\
\text { UnB atendem } \\
\text { objetivos } \\
\text { (D.Ep) }\end{array}$ & $\begin{array}{l}\text { Participação } \\
\text { nas decisôes e } \\
\text { confecção de } \\
\text { normativas } \\
\text { sobre A.E } \\
\text { (D.Ia) }\end{array}$ & $\begin{array}{l}\text { Rotatividade } \\
\text { dos A.S. } \\
\text { ocorre de } \\
\text { forma } \\
\text { planejada } \\
\text { (R.AS) }\end{array}$ & $\begin{array}{l}\text { Incentivos por } \\
\text { parte da gestão } \\
\text { para } \\
\text { capacitação } \\
\text { profissional } \\
\text { (I.Cg) }\end{array}$ & $\begin{array}{l}\text { Comunicação } \\
\text { dentro da } \\
\text { equipe de A.S. } \\
\text { é fluida e } \\
\text { produtiva } \\
\text { (C.Ee) }\end{array}$ & $\begin{array}{l}\text { Novo SAE para } \\
\text { realização de } \\
\text { estudos } \\
\text { socioeconômicos } \\
\text { na. UnB é efetivo } \\
\text { (N.SS) }\end{array}$ \\
\hline $\begin{array}{l}\text { Suficiência } \\
\text { dos recursos } \\
\text { financeiros } \\
\text { do PNAES } \\
\text { destinados a } \\
\text { assistência } \\
\text { estudantil } \\
\text { (R.Fd) }\end{array}$ & $\begin{array}{l}\text { Posicionamento } \\
\text { técnico dos } \\
\text { A.S. é levado } \\
\text { em conta na } \\
\text { tomada de } \\
\text { decisões (P.Ta) }\end{array}$ & $\begin{array}{l}\text { Estrutura } \\
\text { física do } \\
\text { espaço de } \\
\text { trabalho é } \\
\text { adequada } \\
\text { (E.Fa) }\end{array}$ & $\begin{array}{l}\text { Preparação } \\
\text { para o } \\
\text { desenvolvimento } \\
\text { das atribuições } \\
\text { na DDS (P.Da) }\end{array}$ & $\begin{array}{l}\text { Acesso a } \\
\text { pessoas de } \\
\text { niveis } \\
\text { hierárquicos } \\
\text { Superiores é } \\
\text { fácil (A.Ps) }\end{array}$ & $\begin{array}{l}\text { Somente A.S. } \\
\text { devem realizar } \\
\text { estudos } \\
\text { socioeconômicos } \\
\text { (S.AS) }\end{array}$ \\
\hline
\end{tabular}

Nota: Sistema de Assistência Estudantil (SAE); Assistente Social (A.S.); Assistência Estudantil (A.E.)

Nota: Sistema de Assistência Estudantil (SAE); Assistente Social (A.S.); Assistência Estudantil (A.E.)

\subsection{Instrumental analítico}

Os dados mensurados pela Escala de Likert (1932) foram analisados pela Análise de Cluster (AC). Segundo Hair, Black, Babin, Anderson e Tatham (2009), a AC é uma técnica estatística que forma conglomerados de variáveis homogêneas. Nesta pesquisa, aplicou-se essa técnica para analisar o agrupamento das 24 variáveis que compuseram as 06 (seis) categorias pré-definidas.

Como a AC forma grupos de elementos semelhantes, é necessária uma medida de distância entre eles. No intuito de medir a diferença de similaridade do espaço entre as variáveis, utilizou-se a distância euclidiana. A distância euclidiana consiste na raiz quadrada da soma dos quadrados das diferenças de valores para cada variável. Optou-se por essa medida por ser a mais utilizada em pesquisas exploratórias (Hair, Black, Babin, Anderson, \& Tatham, 2009).

Para o desenvolvimento da AC utilizou-se o software Estatistic, versão 10, optando pelo método hierárquico e procedimento Ward para ligação dos clusters e formação dos dendogramas. Hair et al. (2009) mencionam que o método Ward é o mais comum para estudos e representação gráfica dos clusters, pois ele realiza os agrupamentos daqueles que possuem dimensões similares, com variação interna mínima. 
A AC permite uma vasta aplicabilidade por oferecer liberdade de pressupostos estatísticos e não existir nenhum procedimento padrão ou precisão para determinação do número final de clusters a serem interpretados. Assim, assumiu-se três agrupamentos para interpretação dos resultados, distinguindo os grupos de variáveis em: 1) "fatores positivos"; 2) "fatores intermediários" e 3) "fatores negativos" para os processos de trabalho na assistência estudantil da UnB.

\section{Resultados e Discussões}

\subsection{Perfil dos respondentes}

No grupo de assistentes sociais analisados predominou o sexo feminino, com um percentual de $94 \%$ da amostra e idade média de 36 anos, variando entre 27 e 53 anos. A maioria dos participantes possui algum grau de especialização e o tempo médio de experiência profissional na diretoria supramencionada é de quatro anos e um mês, sendo que apenas um participante declarou ter experiência inferior a um ano na DDS (Figura 1).
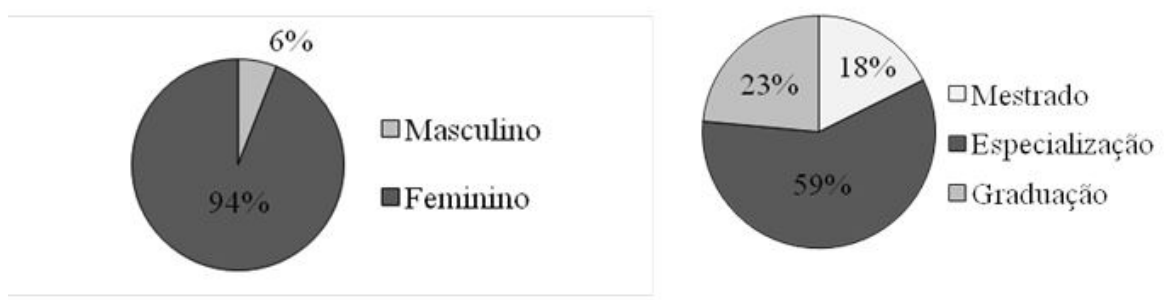

Figura 1 - Distribuição do Sexo e do grau de instrução dos participantes

O perfil dos respondentes demonstrou um grupo de especialistas maduros, experientes e bem formados. Quase que a totalidade dos profissionais são do sexo feminino, estando de acordo com a maior formação de mulheres nos cursos de assistente social.

Cendón, Ribeiro e Chaves (2014, p. 33) destacou a importância da experiência e conhecimento dos respondentes em pesquisas do tipo survey, afirmando que é "possível que não haja formas de se controlarem problemas tais como variações nas habilidades, nível de conhecimento e contexto cultural" da amostra pesquisada. Portanto, nessas situações, o mais importante é disponibilizar as características dos especialistas pesquisados, permitindo o leitor avaliar a validade e limitações dos resultados.

\subsection{Processos de trabalho da assistência estudantil}

\subsubsection{Gestão de políticas educacionais}

A AC agrupou três conjuntos de variáveis dentro da categoria de gestão de políticas educacionais. Somente a variável P.Al (aplicação do PNAES conforme a legislação) foi definida como um fator positivo dentro dos processos de trabalho na assistência estudantil da UnB (Figura 2). 
Figura 2 -Gestão de políticas públicas

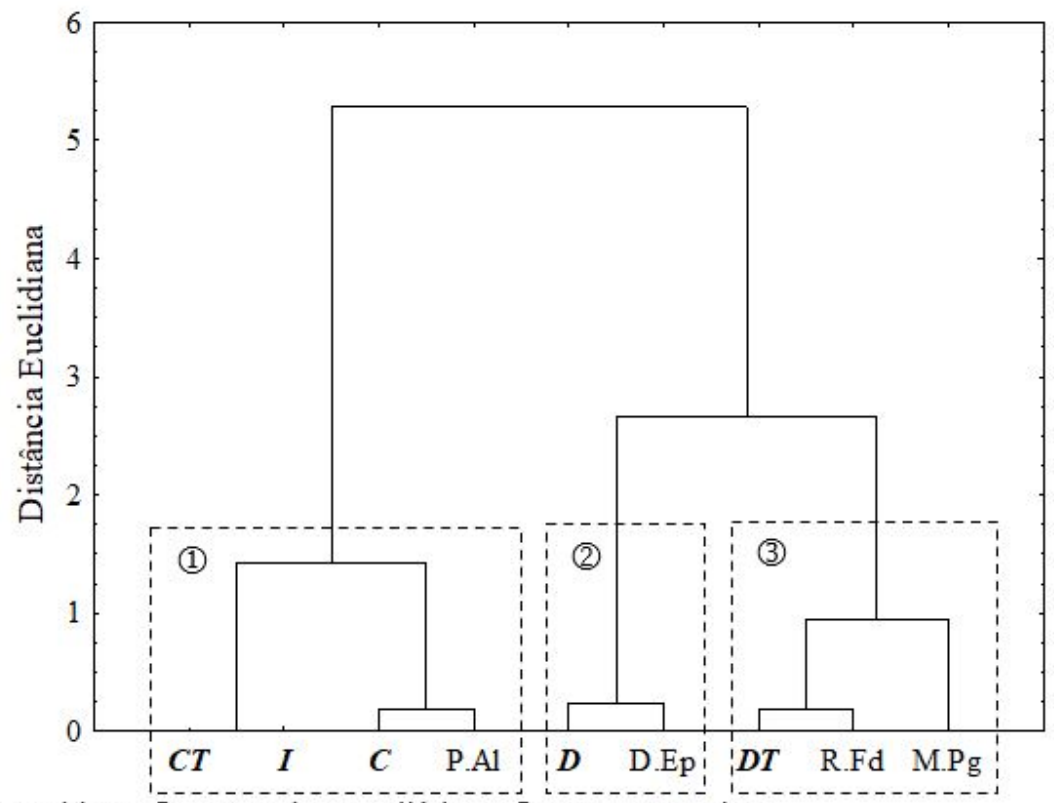

Nota: (1) Fatores positivos; (2) Fatores intermediários e (3) Fatores negativos

\begin{abstract}
Variáveis: Mudanças nas políticas educacionais de ensino superior sem diálogo prévio com as universidades (M.Pg); Recursos financeiros do PNAES destinados a assistência estudantil (R.Fd); Distribuição e execução de valores do PNAES atendem os objetivos (D.Ep); Aplicação do PNAES conforme a legislação (P.Al)
\end{abstract}

Como fatores negativos e que se encontram em piores condições para a categoria de gestão de políticas educacionais, destacaram-se: R.Fd (suficiência de recursos financeiros do PNAES destinados a assistência estudantil) e M.Pg (mudanças nas políticas educacionais de ensino superior sem diálogo prévio com as universidades). A variável D.Ep (distribuição e execução de valores do PNAES atendem os objetivos) foi posicionada junto ao atributo "Discordo", classificada, portanto, de forma negativa, porém, em uma posição intermediária quando comparada às demais variáveis (Figura 2).

Após fazer a relação entre os resultados do dendograma e as justificativas dos participantes nas questões abertas, percebeu-se que, embora a maioria admita clareza quanto ao perfil, metodologia e objetivos do PNAES, não há um consenso sobre essa questão. Algumas opiniões apontaram que as orientações da lei deixam a metodologia do programa a critério de cada instituição, sendo objeto de críticas quanto a uma falta de objetividade e padronização para a sua aplicação, destacando os seguintes comentários:

"A resposta seria concordo em parte. O Programa define o perfil, porém deixa a critério das IFES [Instituições Federais de Ensino Superior] e dos IFs [Institutos Federais de Educação, Ciência e Tecnologia] a metodologia a ser utilizada nos processos de seleção, monitoramento e avaliação dos benefícios que serão aplicados"

"Concordo que a referida Lei está clara acerca de quem é seu público, ainda que não restrinja a metodologia e deixa em função das instituições de ensino"

A descentralização da gestão administrativa do PNAES para as Instituições Federais de Ensino Superior (IFES) está alinhada ao artigo 207 da Constituição Brasileira referente a autonomia universitária (Constituição da República Federativa do Brasil, 1988). Na visão de Deligdisch, Stelzer e Gonçalves (2011), garantir a autonomia universitária é garantir a participação efetiva dos destinatários das políticas universitárias na sua formulação, estando de acordo com o proposto no modelo de gestão pública societal. O modelo societal surgiu como "proposta de soluções às disfunções presentes no modelo gerencial, o qual, 
em princípio, buscava a participação social, porém não conseguiu efetivá-la” (Drumond, Silveira, \& Arlindo Silva 2014, p. 8).

As principais críticas dentro da categoria “Gestão de Políticas Educacionais” foi que os recursos financeiros do PNAES destinados à assistência estudantil não são suficientes para atendimento da demanda dos estudantes e que as mudanças nas políticas educacionais de ensino superior, sem diálogo prévio com as universidades, impactam negativamente nos processos de trabalho. Esses dois aspectos podem ser resumidos na seguinte declaração:

“Temos enfrentado uma grave crise financeira, pouco recurso para uma demanda que só cresce. Perdemos a gestão desse recurso no DAC, que agora encontra-se nas mãos de uma comissão responsável pela definição de prioridades, sem diálogo com a equipe técnica”

Os comentários a respeito da distribuição e execução de valores do PNAES na UnB indicaram uma situação negativa, pois, para muitos, não são atendidos todos os objetivos da lei nessa questão, em especial no que tange à articulação com as atividades de ensino, pesquisa e extensão:

"Pelo valor limitado dos recursos, apenas algumas áreas são atendidas, com foco no auxílio direto, alimentação, moradia, transporte e mais recentemente auxílio creche (o equipamento creche seria mais adequado do que o atendimento em pecúnia). Além da oferta pequena de vagas nos programas que estão sendo atendidos, não existe monitoramento de como está ocorrendo a articulação da assistência estudantil com o ensino, a pesquisa e a extensão"

A partir dos resultados, infere-se que a alta gestão da $\mathrm{UnB}$ não esteja utilizando de meios adequados de informação sobre o direcionamento dos valores do PNAES para outras diretorias que também se beneficiam do recurso, estas também trabalham com ações que contemplam o público-alvo e os objetivos da legislação. Ademais, não há clareza sobre os resultados dessas ações, a fim de saber se estão sendo contempladas em articulação com ensino, pesquisa e extensão. Os problemas relatados foram abordados por Zorzal e Rodrigues (2018), esses autores afirmaram que a boa governança das universidades públicas brasileiras está diretamente relacionada com a transparência de sua gestão, abordando toda a hierarquia de comando e não apenas a chefia imediata.

\subsubsection{Estilo de gestão da DDS}

Para a categoria "Estilo de gestão da DDS" a interpretação foi de que a AC não identificou fatores positivos, conforme a Figura 3. 
Figura 3 -Estilo de gestão da DDS

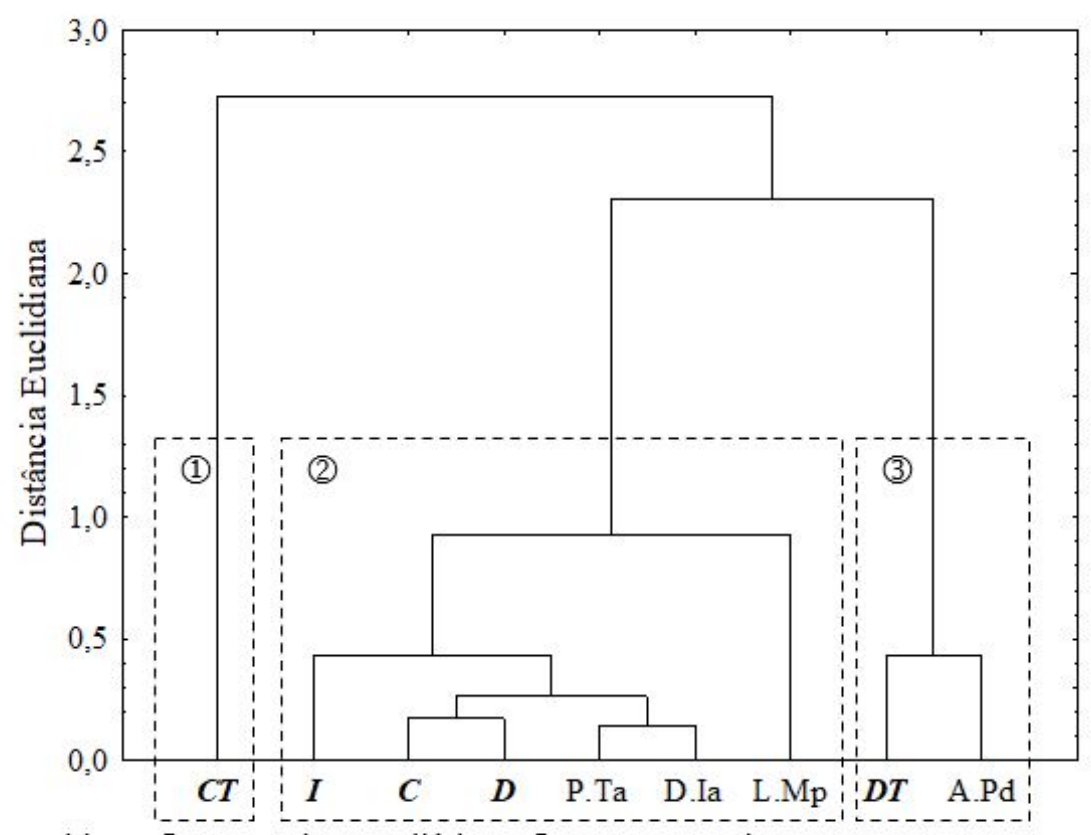

Nota: (1) Fatores positivos; (2) Fatores intermediários e (3) Fatores negativos

\begin{abstract}
Variáveis: Condução da gestão da DDS de forma organizada e planejada (A.Pd); Liberdade para propor modificações sem retaliações (L.Mp); Participação nas decisões e confecção de normativas sobre A.E. (D.Ia); Posicionamento técnico dos A.S. é levado em conta na tomada de decisão (P.Ta)
\end{abstract}

A variável A.Pd (condução da gestão da DDS de forma organizada e planejada) foi a única que sobressaiu como um fator negativo aos processos de trabalho da assistência estudantil. As demais variáveis L.Mp (liberdade para propor modificações sem retaliações), D.Ia (participação nas decisões e confecção de normativas sobre assistência estudantil) e P.Ta (posicionamento técnico dos assistentes sociais é levado em conta na tomada de decisão) foram classificadas como fatores intermediários e, portanto, em situação relativamente melhor a A.Pd.

Baldam et al. (2014) definiram como aspectos críticos para uma gestão efetiva a existência de apoio e reconhecimento aos colaboradores. Sem o apoio e reconhecimento, não é possível esperar resultados eficazes em uma organização. Fato explicitado em algumas descrições dos participantes e que explicam os resultados da Figura 3:

"Falta organização na gestão. Não é claro o seu papel e a sua posição hierárquica o que dificulta a organização e o planejamento. Como pode ter que convocar toda uma equipe de trabalho para analisar e formular editais e resoluções? As discussões tornamse demoradas e pouco produtivas. Falta a gestão ter poder decisivo diante das questões colocadas. As vezes tenho a impressão de não ter gestão"

"A falta de autonomia e dificuldade de planejamento que a DDS vem sofrendo deveria ser compensada com maior aproximação do DAC e com mais alinhamento da equipe, mas não é o que acontece"

Entre outros motivos, a percepção dos participantes é motivada pela falta de transparência da alta gestão, especialmente sobre os dados financeiros e orçamentários recebidos pelo PNAES e a sua distribuição entre as diversas diretorias contempladas na UnB. Esse fato fragiliza a relação da equipe com a atual gestão da DDS, tendo em vista que não se sabe qual é a autonomia destinada a essa diretoria por seus superiores. Os resultados encontram-se alinhados com a preocupação de Possamai e Souza (2020), que destacaram os renitentes desafios que se interpõem à transparência e o acesso à informação no setor público. 


\subsubsection{Estruturas e normas}

Conforme a Figura 4, referente à categoria de estruturas e normas, a única variável que se relacionou como um fator positivo foi E.Fa (estrutura física do espaço de trabalho é adequada). Destacou-se como fator negativo aos processos de trabalho a variável Q.As (quantidade de assistentes sociais atendem à demanda). Já os itens O.Fa (orientações formais e claras sobre as atribuições dos assistentes sociais) e R.As (rotatividade dos assistentes sociais ocorre de forma planejada) se enquadraram como fatores intermediários pela AC.

Figura 4 -Estruturas e normas

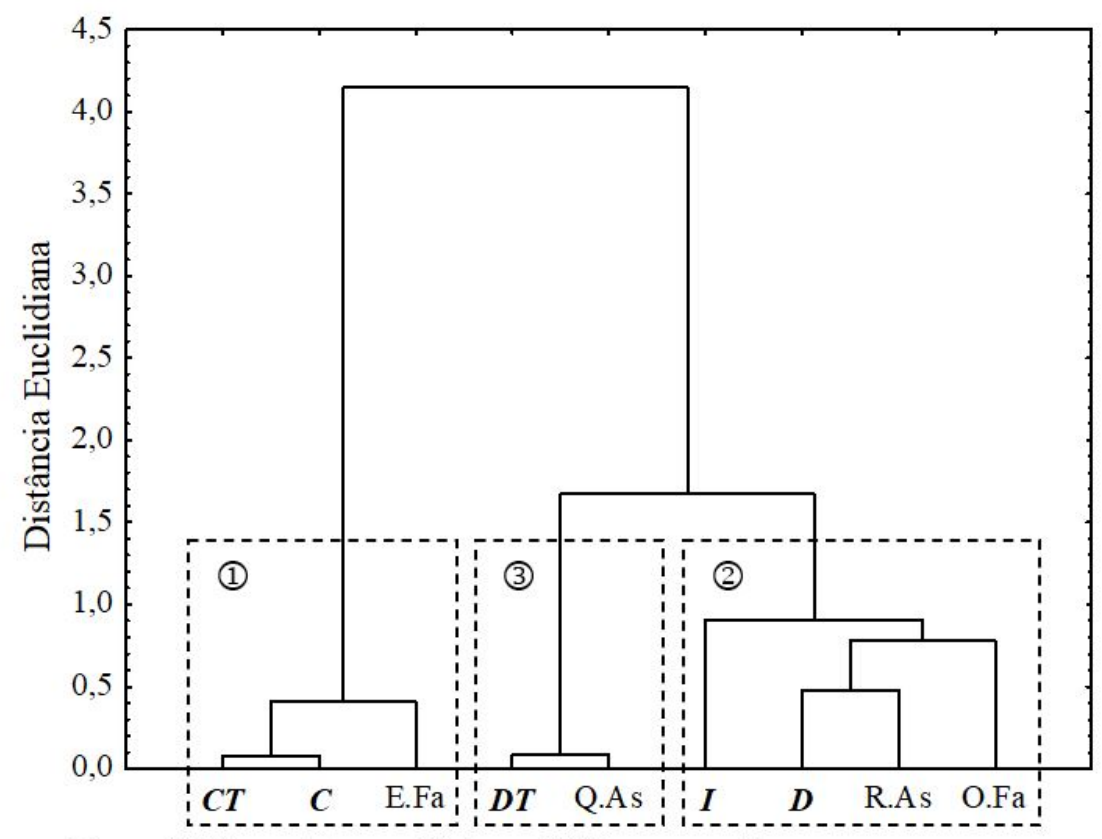

Nota: (1) Fatores positivos; (2) Fatores intermediários e (3) Fatores negativos

Variáveis Orientações formais e claras sobre as atribuições dos A.S. (O.Fa); Rotatividade de A.S ocorre de forma planejada

(R.As); Quantidade de A.S. atendem à demanda (Q.As); Estrutura física do espaço de trabalho é adequada (E.Fa).

No conjunto de variáveis desta categoria, a estrutura física foi relacionada como um fator positivo pelos participantes. Acredita-se que esse resultado esteja associado a maior parte da equipe realizar suas atividades em prédios novos e adequados as necessidades de trabalho da assistência estudantil.

Quanto ao número de assistentes sociais, percebeu-se uma insatisfação geral nas respostas, já que como verificado, a demanda de estudante e as ações desempenhadas por esses profissionais são inversamente proporcionais, causando prejuízos diversos conforme os seguintes relatos:

"A demanda estudantil é maior do que a capacidade da equipe em atender, o que sobrecarrega o trabalho das profissionais e leva, inclusive, ao adoecimento, tendo em vista as especificidades dos atendimentos que são realizados"

"Há muito trabalho em todos os campi e CEU, seriam necessários mais assistentes sociais para todas as demandas de avaliações socioeconômica, emergenciais, acompanhamento acadêmico, atendimento psicossocial, articulação com a rede etc. Não conseguimos fazer tudo que é necessário. Há uma dificuldade maior de conciliar o trabalho do assistente social com a falta de pessoal administrativo, o que sobrecarrega ainda mais o assistente social"

Almeida, Neres, Nunes e Souza (2020, p. 460) abordaram dificuldades de gestão em consequência da expansão de vagas nas universidades públicas, para os autores "a relação custo/benefício da política de ampliação e democratização das vagas do ensino superior no Brasil, caso essa não seja bem planejada e 
implementada, pode levar a resultados desfavoráveis e não contribuir para o alcance dos seus objetivos no longo prazo".

Observou-se também que a DDS não possui planejamento e normativas adequadas para um bom funcionamento. Nesse aspecto, Silveira (2018) destacou que "os atos normativos serão mais ou menos eficazes na sua execução quanto melhor possam ser apreendidos pelos seus destinatários”. Essa observação esteve alinhada a percepção dos assistentes sociais pesquisados, destacando a seguinte declaração:

"Sinto muita falta dessas orientações formais. Construímos recentemente um instrumental sobre o estudo socioeconômico, mas precisamos avançar no seu aprimoramento, buscando uma fundamentação teórica mais aprofundada. Percebo ainda como desafio. Assim como a ausência de um Plano de Trabalho dos/das Assistentes Sociais, conforme orientação do conjunto CFESS/CRESS”

\subsubsection{Treinamento e capacitação}

Na categoria de "Treinamento e Capacitação", a AC distribuiu as variáveis nas três classificações prédefinidas: fatores positivos, negativos e intermediários. A única variável classificada como positiva foi I.Cg (incentivos por parte da gestão para capacitação profissional). A variável P.Tr (existência de política de treinamento aos novos profissionais do setor) foi considerada como a que está em pior condição, pois foi a única que se agrupou junto ao atributo "Discordo Totalmente" na AC. As duas outras variáveis I.Ps (recebimento de informações sobre os processos de trabalho no ingresso ao setor) e P.Da (preparação para o desenvolvimento das atribuições na DDS) posicionaram-se como fatores intermediários (Figura 5).

Figura 5 -Treinamento e capacitação

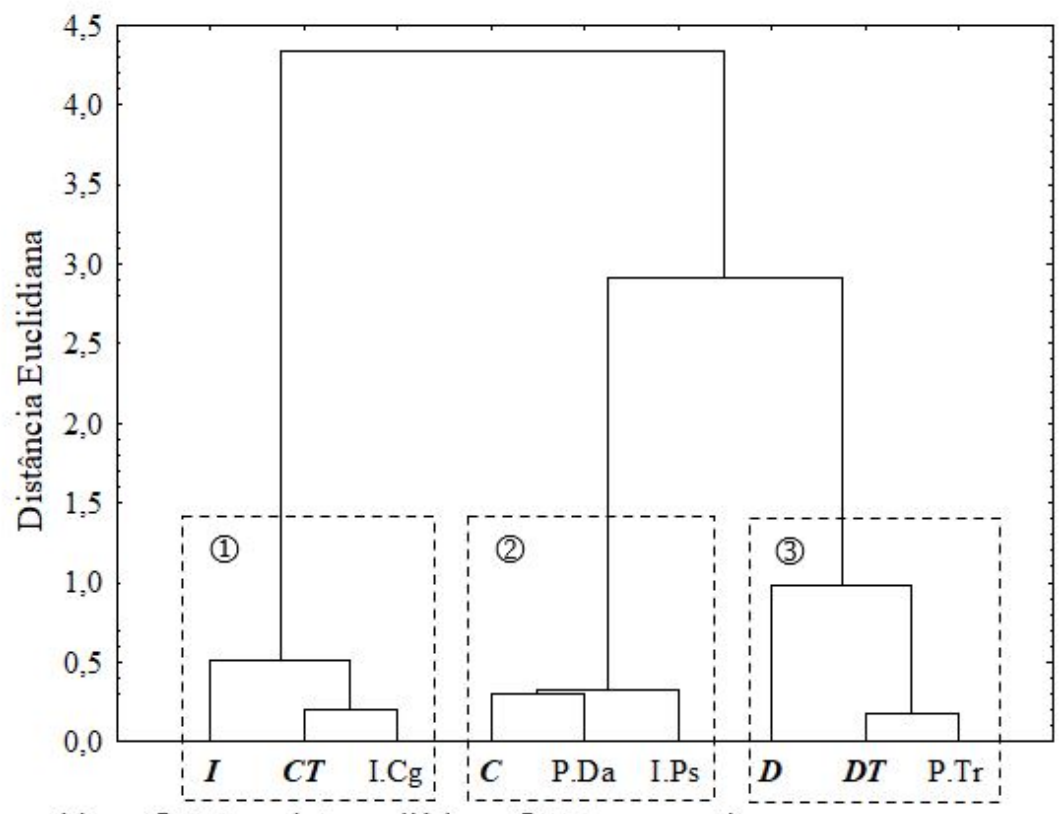

Nota: (1) Fatores positivos; (2) Fatores intermediários e (3) Fatores negativos

\footnotetext{
Variáveis: Política de treinamento do setor (P.Tr); Informações sobre os processos de trabalho no ingresso ao setor (I.Ps); Preparação necessária para o desenvolvimento das atribuições na DDS (P.Da); Incentivos por parte da gestão para capacitação profissional (I.Cg).
}

Nesta categoria, verificou-se como principal problema a DDS não possuir uma política de treinamento para os servidores ao ingressarem no setor. As demais variáveis desta categoria acabaram sendo reflexo desse 
problema, ainda que em menor proporção. Em relação ao treinamento e capacitação da equipe, destacaramse as seguintes opinióes:

“Os ‘treinamentos' são realizados de maneira informal, conforme disponibilidade de outras profissionais. Apesar do esforço em sistematizar documentos com orientações sobre os processos de trabalho das assistentes sociais, esse ainda é um desafio para a equipe"

"Acabamos aprendendo com a prática, acompanhando outros profissionais, porém não temos treinamento estruturado"

A percepção positiva quanto à existência de incentivos para capacitação pode ter sido motivada pelo apoio da gestão na liberação dos servidores do trabalho e não por motivações relacionadas a ganhos de produtividade, conforme a observação de um participante: "Acredito que se solicitado, haverá liberação, mas vejo pouco incentivo em termos de divulgação e oferta de momentos formativos".

Capacitação e treinamento são essenciais para o desenvolvimento e qualidade das ações desempenhadas num processo de trabalho. Entretanto, é preciso observar as preocupações de Carmen (2019), refletindo sobre a promoção de treinamentos que observam prioritariamente os interesses dos colaboradores e não a sua utilidade para a organização pública.

\subsubsection{Comunicação}

Apenas C.Ee (comunicação dentro da equipe de assistentes sociais é fluida e produtiva) se apresentou como um fator positivo na categoria de "Comunicação". As variáveis restantes: F.Ai (facilidade no acesso as informações sobre assistência estudantil), F.Qr (frequência e quantidade de reuniões são suficientes) e A.Ps (acesso a pessoas de níveis hierárquicos superiores é fácil) foram definidas como fatores intermediários. Nenhuma variável se caracterizou como um fator negativo na categoria de "Comunicação" (Figura 6).

Figura 6 -Comunicação

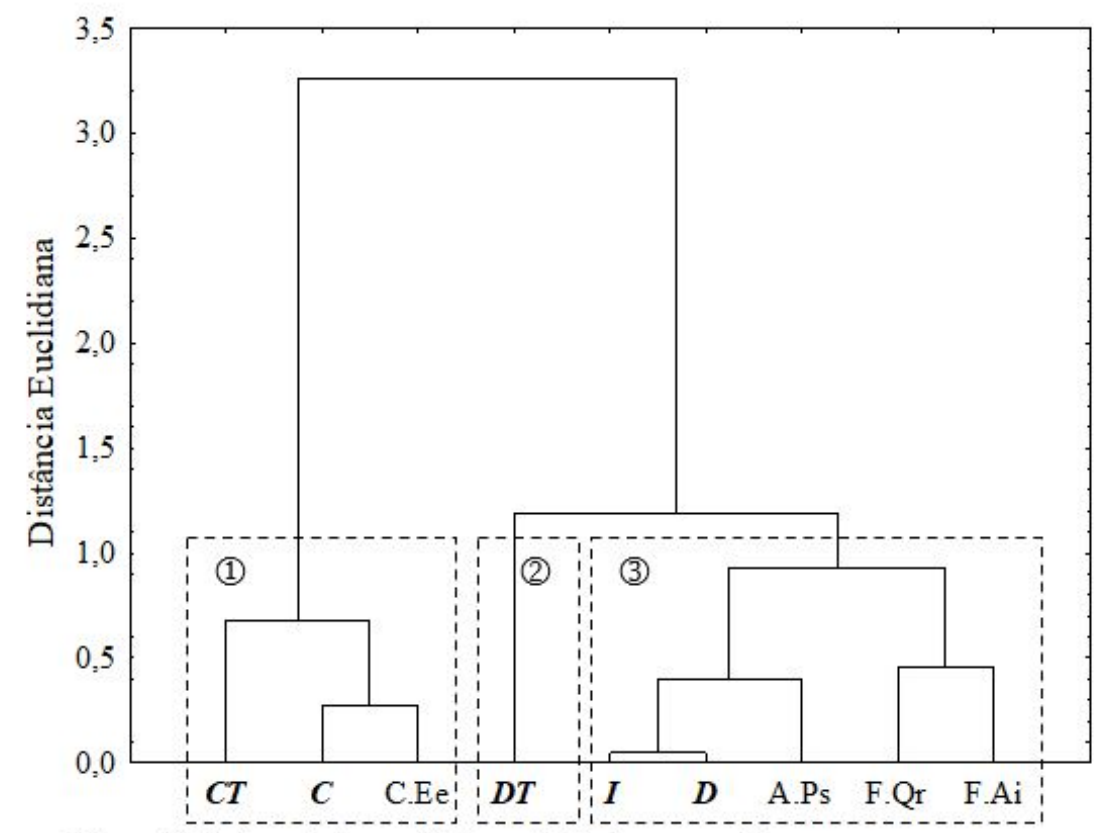

Nota: (1) Fatores positivos; (2) Fatores intermediários e (3) Fatores negativos 


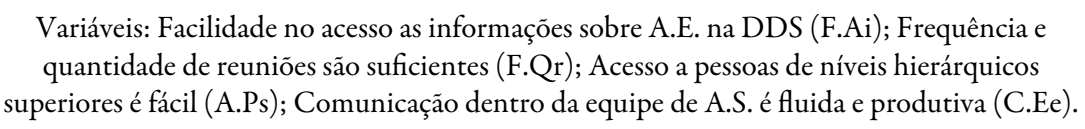

Em relação a comunicação na DDS destacaram-se os seguintes comentários:

\begin{abstract}
"Sim, tenho tido trocas importantes com as colegas na reflexão de situações e na busca de alternativas para atendimento das demandas trazidas pelos estudantes"

"Dá para contar com a experiência de muitos colegas Assistentes Sociais até alguns técnicos e estes contribuem com o trabalho, entretanto o volume de trabalho nem sempre propicia uma conversa de qualidade, pois hoje urge seguir metas e cronogramas 'robotizantes"

"A quantidade de reuniôes oscila ao longo do semestre em função do processo de seleção dos estudantes. Elas, entretanto, têm em sua maioria restringindo-se a ajustes nos editais e, em caráter mais excepcional, a ajustes no instrumental de uniformização da avaliação socioeconômica. Sinto falta de reuniões para estudo de casos e definição de estratégias/fluxos para além do setor"
\end{abstract}

Sob o prisma da comunicação, a pesquisa mostrou que, em relação às “trocas profissionais” voltadas para dúvidas e discussões momentâneas dentro da equipe de assistentes sociais, têm sido positivas e acontecido a contento. Para Bernardino e Santos (2020), dentro da gestão de recursos humanos nas organizações sociais em Portugal, a cooperação entre e dentro das equipes de trabalho é fundamental diante dos desafios que a atividade social impõe.

Todavia, as demais variáveis indicaram aspectos que podem ser aprimorados, especialmente em relação a comunicação vertical com superiores. A relevância da comunicação no desempenho organizacional é ressaltada por Kunsch (2018, p. 16), tratando-a como um elemento a ser trabalhado no planejamento estratégico das organizações.

A comunicação clássica, instrumental, exclusivamente técnica e operacional não atende mais às demandas das organizações no novo ambiente socioeconômico e político. Responsabilidade social pública, preservação do planeta por meio de um desenvolvimento sustentável, respeito à diversidade, transparência, ética, valores intangíveis etc. são imperativos que norteiam os comportamentos institucionais e, consequentemente, exigirão uma comunicação organizacional muito mais proativa e estratégica (Kunsch, 2018, p. 16).

\title{
4.2.6 Instrumentais utilizados
}

As variáveis inerentes aos instrumentais utilizados pelos assistentes sociais na DDS se apresentaram em diferentes situações. As variáveis P.Ic (padronização nos instrumentais para todos os campi) e N.Ss (novo SAE para realização de estudos socioeconômicos na UnB é efetivo) foram identificados como fatores positivos. O item T.Pa (teoria como diferente da prática no trabalho) foi classificado como um fator intermediário (Figura 7). 
Figura 7 - Instrumentos utilizados

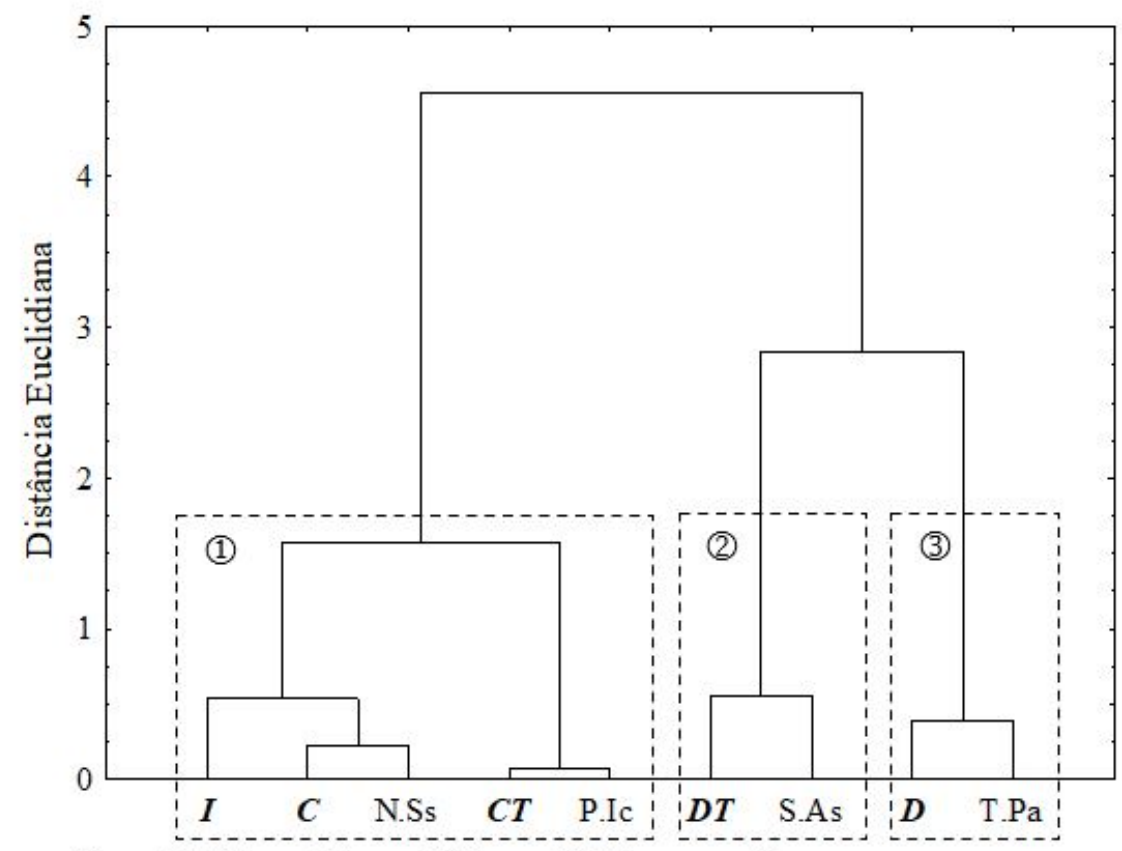

Nota: (1) Fatores positivos; (2) Fatores intermediários e (3) Fatores negativos

Variáveis: Teoria como diferente da prática no trabalho (T.Pa); Somente A.S. devem realizar
estudos socioeconômicos (S.As); Padronização nos instrumentais para todos os campi
(P.Ic); Novo SAE para realização de estudos socioeconômicos na UnB é efetivo (N.Ss).

A exclusividade dos assistentes sociais na realização dos estudos socioeconômicos (S.As), que é determinante para inclusão dos estudantes nos programas de assistência estudantil, não contou com o apoio do grupo pesquisado. Essa discordância pode ser interpretada como um aspecto positivo, denotando um menor corporativismo na área. Por outro lado, também pode ser interpretada como um aspecto negativo, ao ponto que relaciona o estudo socioeconômico como um processo burocrático e cartorial, podendo ser desenvolvido por qualquer profissional que tenha um treinamento prévio, independente da sua área de formação.

A importância de uma padronização dos instrumentais de trabalho foi percebida nas manifestações dos participantes, destacando a seguinte declaração:

“A padronização objetiva um critério de justiça para com o usuário assim como um alinhamento entre as diferentes nuances ou alinhamentos da ação profissional no intuito de assegurar o máximo de isonomia possível. É mediante o processo de construção das padronizações de instrumentais e rotinas que ampliamos nossa capacidade de percepção sobre as particularidades de nossa demanda e damos um encaminhamento coletivo/consensual a elas. A padronização deve ser, contudo, uma referência e não um grilhão. Emergem da prática cotidiana, cedo ou tarde, situações impensadas”

Compreende-se que a padronização dos instrumentais permitiria uma maior transparência no trabalho desenvolvido, ajustando a sua adequação à realidade de cada campus. Por outro lado, não pode perder de vista a especificidade de cada caso e transformar o trabalho do assistente social em uma simples conferência de documentos. Trindade (2004) realizou uma reflexão sobre o instrumental técnico-operativo do Serviço Social, destacando a subjetividade dos seus resultados e criticando a sua aplicação de forma padronizada.

Ressalta-se que as opiniões dentro desta categoria foram bastante heterogêneas, sugerindo fragilidade sobre os conhecimentos teórico-metodológicos, bem como sobre as atribuições privativas da equipe de Servidores Sociais da DDS. Na sequência alguns comentários que ilustram essa diversidade de opiniões: 


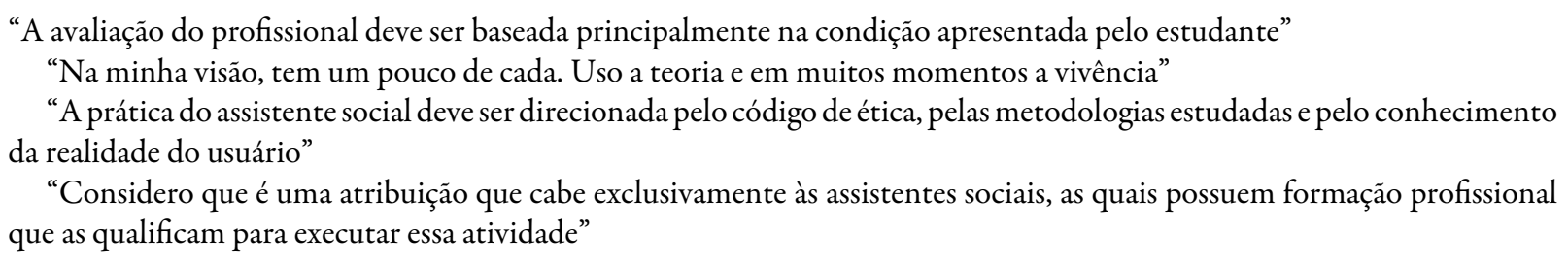

Guerra (2009) avaliou que não houve, por parte do Serviço Social, um processo de apropriação das diretrizes da profissão, o que gera a ideia de separação entre o ensino teórico do ensino prático, e isso pode contribuir para numa visão distorcida e dicotômica dessas duas dimensões.

Destaca-se que o código de ética da profissão não elenca os estudos socioeconômicos como atividade profissional privativa do assistente social. De acordo com o Conselho Federal de Serviço Social (CFESS) (2012), os assistentes sociais são profissionais capacitados para realizar estudos socioeconômicos para fins de benefícios e serviços e, portanto, o insere como competência relacionada à profissão.

\section{Considerações Finais}

Percebeu-se um aumento importante da demanda de estudantes que solicitaram a assistência estudantil nos últimos anos, decorrente da expansão e democratização do acesso à universidade, refletindo impactos negativos nos processos de trabalho dos assistentes sociais da $\mathrm{UnB}$, pois a estrutura da $\mathrm{UnB}$ não tem acompanhado essa expansão, de forma a garantir qualidade e celeridade nos processos de trabalho.

No entanto, antes de se pensar em nomear novos servidores e aumentar a equipe, seria importante a realização de uma revisão dos processos de trabalho internos. Conforme os resultados, poucas variáveis apresentaram-se como fatores positivos, demonstrando que existe muito a ser feito na gestão dos processos de trabalho analisados. Faz-se necessário, além da identificação das dificuldades, pensar em estratégias para melhoria das ações desenvolvidas, a fim de evitar uma possível fragilização de execução do trabalho, permitindo difusão dos conhecimentos e preenchendo as lacunas existentes.

Algumas ações que podem ser essenciais e, possivelmente, permitirão um amplo espaço para a melhoria dos processos de trabalho são: 1) o planejamento das atividades da diretoria como um todo; 2) oportunidade de participação dos servidores nas reuniões estratégicas e comissões sobre dados orçamentários destinados a assistência estudantil; 3) estruturação de normativas sobre objetivos institucionais e atribuições por especialidade profissional; 4) reuniões periódicas entre a equipe técnica e reuniões administrativas com participação de gestores; 5) ampliação dos canais de comunicação entre as equipes dos campi; 6) padronização de instrumentais e implantação de uma política de treinamento tanto no ingresso de novos servidores como no oferecimento de reciclagens profissionais para a equipe já existente; 7) maiores incentivos as capacitações voltadas às áreas de atuação e 8) organização do fluxo de eventuais saídas de servidores e investimentos em sistemas operacionais mais inteligentes e menos burocráticos.

Acredita-se que, na ausência dos fatores supracitados, pouco irá adiantar a ampliação da equipe, pois os processos de trabalho encontram-se comprometidos pela falta de uma gestão interna. Além disso, o aumento da equipe por si só não conseguirá alcançar o número ideal de profissionais para atendimento de uma demanda que têm crescido sistematicamente. Dessa forma, apresentar-se-ão outros fatores desfavoráveis, como a estrutura física e os equipamentos necessários à realização do trabalho.

Faz-se mister destacar que, na releitura dos processos de trabalho da assistência estudantil da UnB, também seria importante avaliar se apenas os servidores com formação superior em Serviço Social continuarão realizando, de forma exclusiva, os estudos socioeconômicos. Conforme verificado neste estudo, esta atribuição não é mencionada no código de ética do Serviço Social como privativa aos seus profissionais. Sabe-se também que a UnB conta com uma equipe multidisciplinar e possui outros profissionais da área de 
humanas que poderiam contribuir nessa atividade, como os psicólogos, pedagogos e técnicos em assuntos educacionais, pois possuem formação profissional em área de humanas ou afins.

Diante do exposto, verificou-se a urgência que se coloca para a UnB na busca por processos de trabalho mais efetivos, na perspectiva de acompanhar as transformações ocorridas nos últimos anos, no sentido da modernização das ações, celeridade e manutenção da qualidade.

\section{REFERÊNCIAS}

Almeida, A. N., Neres, I. V., Nunes, A. \& Souza Júnior, C. V. N. (2020). Effectiveness of public university expansion in Brazil: comparison between the situation of graduated and dropout students. Ensaio: Avaliação e Politicas Públicas em Educação, 28 (107): 457 - 479.

Almeida, A. N. \& Silva, P. V. (2020). Desempenho acadêmico e as dificuldades dos estudantes em vulnerabilidade socioeconômica. Revista Temas em Educação, 29 (1): pp. 76-94.

Baldam, R., Valle, R. \& Rozenfeld, H. (2014). Gerenciamento de Processos de Negócio - BPM: Uma referência para implantação prática. Rio de Janeiro: Elsevier.

Bernardino, S.J. Q. \& Santos, J. F. (2020). Práticas de gestão de recursos humanos nas organizações sociais em Portugal: Um estudo exploratório. Administração Pública e Gestão Social, 12 (1): pp.1-23.

Biazzi, M. R., Muscat, A. R. N. \& Biazzi, J. L. (2011). Modelo de aperfeiçoamento de processos em instituições públicas de ensino superior. Gestão \& Produção, 18 (4): pp. 869-880.

Bresser-Pereira, L. C. (2007). Burocracia pública e classes dirigentes no Brasil. Revista de Sociologia e Política, 28: pp. 9-30.

Carmen, P.N. (2019). Retos de futuro en la gestión de los recursos humanos públicos en España.Administração Pública e Gestão Social, 11 (4): pp. 1-19.

Castro Silva, R. R. C. \& Mattia, C. (2016). Ciência administrativa e gestão pública: uma crítica à primazia do privado em relação ao público. Cadernos EBAPE, 14 (4): pp. 1054-1065.

Cendón, B. V., Ribeiro, N. A. \& Chaves, C. J. (2014). Pesquisas de survey: análise das reações dos respondentes. Informação \& Sociedade: Estudos, 24 (3): pp. 29-48.

CFESS. (2012). Código de ética do/a assistente social. Lei 8.662/93 de regulamentação da profissão. 10a ed. Brasilia: Conselho Federal de Serviço Social. Disponível em: http://www.cfess.org.br/arquivos/CEP_CFESS-SITE.pdf;. Acesso em 20 de março de 2019.

Cordeiro, W. M. (2017). Burocracia na construção da administração pública do século XXI: uma reflexão teórica. In: IV Encontro Brasileiro de Administração Pública. A construção da Administração Pública do Século XXI, 2017, João Pessoa - PB, Anais... João Pessoa - PB.

Costa, L. A. \& Rocha, D. F. (2018). Burocracia e gestão pública: uma análise do Ministério da Saúde. Cadernos Brasileiros de Terapia Ocupacional, 26 (3): pp. 632-645.

Decreto n. 6.096, de 25 de abril de 2007. (2007, 25 abril) Programa de Apoio a Planos de Reestruturação e Expansão das Universidades Federais - REUNI.

Decreto n. 7.234, de 19 de julho de 2010. (2010, 19 julho) Programa Nacional de Assistência Estudantil - PNAES. Brasília, 19 de julho de 2010.

Deligdisch, M. E., Stelzer, J. \& Gonçalves, E. das N. (2011). Autonomia universitária e políticas públicas: indissociável participação da sociedade. In: XI Colóquio Internacional sobre Gestão Universitária na América do Sul, 2011, Florianópolis. Anais eletrônicos... Florianópolis - SC: Gestão da Internacionalização, da Cooperação e da Cultura na Educação Superior.

Drumond, A. M., Silveira, S. de F. R. \& Arlindo Silva, E. (2014). Predominância ou coexistência? Modelos de administração pública brasileira na Política Nacional de Habitação. Revista de Administração Pública, 48 (1): pp. 3-25. 
Dutra, N. G. R. \& Santos, M. F. S. (2017). Assistência estudantil sob múltiplos olhares: a disputa de concepções. Ensaio: avaliação e políticas públicas em educação, 25 (94): pp. 148-181.

Emenda Constitucional n..95, de 15 de dezembro de 2016. (2016, 15 dezembro) Altera o ato das disposições constitucionais transitórias, para instituir o novo regime fiscal, e dá outras providências. Diário Oficial da União, Brasília, v. 153, n. 240, p. 2, 16 dez. 2016. Seção 1.

Constituição da República Federativa do Brasil de 1988. Brasília: Assembleia Constituinte, 1988.

Ferreira da Silva, F. L. \& Almeida, A. N. (2020). Gestão de riscos na área de pessoal à luz da emenda constitucional 95/2016: uma aplicação para a Universidade de Brasília. Revista Gestão Universitária na América Latina GUAL, 13 (3): pp. 232-255.

Ferreira, M. (2020). Assistência estudantil: uma avaliação a partir do desempenho acadêmico dos discentes da UnB. $54 \mathrm{f}$. Dissertação (Mestrado Profissional em Gestão Pública) - Universidade de Brasília, Brasília.

Gonçalves, J. E. L. (2000). Processo, que processo? Revista de administração de empresas, 40 (4): pp. 8-19.

Guerra, Y. (2000). Instrumentalidade no trabalho do Assistente Social. In. Capacitação em Serviço Sociale política social. Módulo 4: O trabalho do Assistente Social e as políticas sociais. Brasília: UnB - CFESS/ABEPSS/CEAD.

Guerra, Y. (2009). A dimensão investigativa no exercício profissional. In. Serviço Social: direitos sociais e competências profissionais. Brasília: CFESS/ABEPSS.

Hair, Jr. J. F., Black, W. C., Babin, B. J., Anderson, R. E. \& Tatham, R. L.; Análise multivariada de dados. 6. ed., Porto Alegre: Bookman; 2009.

Iamamoto, M. V. (2015). O Serviço Social na Contemporaneidade: trabalho e formação profissional. 26. ed. São Paulo, Cortez.

Kunsch, M. M. K. (2018). A comunicac\#a\#o estrate\#gica nas organizac\#ões contemporâneas. Media \& Jornalismo, 18 (33): pp. 13-24.

Lei n. 12.711, de 29 de agosto de 2012. (2012, 29 agosto) Dispóe sobre o ingresso nas universidades federais e nas instituições federais de ensino técnico de nível médio e dá outras providências. Brasília, 2012.

Leite, L. Q. (2016). Reflexões teóricas sobre modelos de Gestão Pública: o paradigma weberiano, a New Public Management e o Estado Neo-Weberiano. Revista de Pesquisa em Politicas Públicas, 7 (1): pp. 80-95.

Likert, R. (1932). A technique for the measurement of attitudes. Archives of Psychology, 22 (140): pp. 1-55.

ssamai, A. J. \& Souza, V. G. (2020). Transparência e dados abertos governamentais: possibilidades e desafios a partir da lei de acesso à informação. Administração Pública e Gestão Social, 12 (2): pp. 1-20. Raichelis, R. (

Possamai, A. J. \& Souza, V. G. (2020). Transparência e dados abertos governamentais: possibilidades e desafios a partir da lei de acesso à informação. Administração Pública e Gestão Social, 12 (2): pp. 1-20.

Raichelis, R. (2011). O assistente social como trabalhador assalariado: desafios frente as violações de seus direitos. Serviço Social \& Sociedade, 107: pp. 420-437.

Silveira, J. T. (2018). Problemas habituais de legística na preparação e redação de leis e regulamentos. Revista eletrônica de direito público, 5 (3): pp. 134-158.

Sousa, C. T. (2008). A prática do assistente social: conhecimento, instrumentalidade e intervenção profissional. Emancipação, 8 (1): pp. 119-132.

Trindade, R. L. P. (2004). Desvendando as Determinações Sócio-históricas do Instrumental técnico-operativo do Serviço Social na Articulação entre Demandas Sociais e Projetos Profissionais. Revista Temporalis, 2 (4): pp. 21-39.

UnB. (2020). Universidade de Brasilia. Disponível em: www.unb.br. Acesso em: 15 de julho de 2020.

Zorzal, L. \& Rodrigues, G. M. (2015). Transparência das informações das universidades federais: estudo dos relatórios de gestão à luz dos princípios de governança. Biblios, 61: pp. 1-18. 